Community energies under-evaluated: Drug initiatives on the margins

Susan Eley Morris PhD and Rowdy Yates MBE

Department of Applied Social Science, University of Stirling

Stirling FK9 4LA, Scotland, United Kingdom

Running title: community-led responses to drugs

Address for corresponding author

Dr Susan Eley Morris

Department of Applied Social Science

University of Stirling

Stirling FK9 4LA

Scotland

United Kingdom

Tel: +44 (0) 1786467986

Fax: + $44(0) 1786457691$

e-mail: $\underline{\text { s.e.morris@stir.ac.uk }}$

Community energies under-evaluated: Drug initiatives on the margins 
Abstract

This article draws together an effectiveness review of community responses to drug concerns and supplementary interviews with key informants. Despite accessing nearly 300 publications relating to initiatives, there is a paucity of published evaluative evidence. The literature does provide a greater amount of information about initiatives that are delivered into the community as opposed to initiated by the community. Community-led responses have taken a number of approaches. To assess the current evidence on 'what works?', we have defined community responses to drug problems under five banners - self-help groups, parents' groups, residents' groups, community development groups and diversionary activity groups - for ease of discussion. There are a number of commonly identified elements that exist in successful and sustainable initiatives which are discussed. 
Community energies under-evaluated: Drug initiatives on the margins

Introduction

Drug use, drug dealing and drug-related crime concerns the general public across the UK (Leitner, Shapland and Wiles 1993). Community responses to drug concerns do not form a neat, homogeneous group so it is unsurprising that, to date, there are no published reviews, systematic or otherwise, from the UK or elsewhere, on community led initiatives in response to drug concerns.

This article draws heavily on a recently conducted effectiveness review (Yates, Morris and Pratt 2000) and supplementary interviews with key informants conducted by the authors. In this article we will argue that the marginalisation of community-led groups within the portfolio of drug prevention and treatment services has inevitably led to the paucity of empirical research on their efficacy. Although a number of significant policy documents (Scottish Office, 1994; HM Government 1998; Scottish Office, 1999) have emphasised the value of harnessing community concerns through community-led action, there is little evidence that this enthusiasm is built upon a rigorous analysis of the efficacy of such initiatives. Indeed, the discrepancy between the apparent endorsement of the approach and the effectiveness evidence is even more marked than that identified in respect of peer-led approaches (Parkin and McKeganey, 2000).

Towards an understanding of types of initiatives 
Community responses to drugs are so varied and so variable, that they can be categorised adequately only on an individual case basis on the rather unsatisfactory belief that "whilst you may not be able to describe what it is, you will certainly know one when you see it".

This difficulty is partially compounded by the use of the word "community" by the statutory sector to describe and define a variety of its own services which are provided outside the hospital campus or area office. But also community initiatives will almost inevitably change over time. For instance, an initiative inspired by the local community, if welcomed and supported by the health board and/or the social work department, might lead to the secondment of statutory sector staff to support it or to funding being made available to reinforce its work. Therefore an initiative of this kind can become part of the treatment response "establishment" to which it was itself a response - at least in part -in a relatively short period of time. Thus, Synanon, a therapeutic community established by a small group of former drug users in the late 1950 's was so enthusiastically welcomed that by the turn of the century, Synanonstyle treatments were available worldwide in more than fifty countries (Kooyman, 2000) although, significantly, the model, once viewed as radical and daring, is increasingly viewed as being located on the orthodox wing of drug treatment provision. 
Evaluating community-led drug initiatives

In our recent effectiveness review we found that despite accessing nearly 300 publications relating to initiatives, evaluation reports and descriptive journal articles are sparse (Yates, Morris and Pratt 2000).

The field of evaluation of initiatives aimed at behavioural and/or cultural change draws heavily on the method of evidence-based medicine within the field of clinical effectiveness. The traditional 'gold standard' of the randomised controlled trial for a hospital based intervention does not transfer well to community based programmes, initiatives and projects where there is little or no control over environmental factors, outcome measures are 'less hard' and social interventions, as opposed to medical interventions, require a longer timescale to make a significant difference to behaviour.

A myriad of organisational factors may contribute to why community responses to drug problems appear to be under-evaluated. These include; a reliance on individuals, misplaced energies, timeframes, size and individuality, suspicion and hostility and freezing out.

Often such initiatives are reliant on the energies of a 'social entrepreneur' or a small group of core members. Where this "inspiration base" loses heart, burns out, or for some reason leaves the group, the remainder, not uncommonly ceases to function in any meaningful way. This can make sustained evaluation difficult to achieve and (as above) difficult to justify in terms of cost. 
Some groups may focus all their energies on the development of an initiative as a defensive shield against other issues that might be too painful to address. Such group members will be reluctant to engage in evaluation for fear of the probability that this dichotomy might become apparent and need to be addressed.

Community-led drug initiatives are often difficult to sustain; particularly where no funding is available to support the administration. Moreover, members may cease their involvement following the resolution of a particular personal problem. Planners are often reluctant to commit scarce resources to initiatives which may not be enduring. Most community-led initiatives have, until recently, been regarded as too insignificant to be of interest to the academic community. Indeed the individuality of the work of these groups has made it difficult to undertake studies.

Initiative individuality may coexist with a critical edge towards existing provision. Many community-led initiatives may be suspicious of and hostile towards the statutory sector especially if they perceive their needs to be unmet. This will inevitably mean that there will be a reluctance to co-operate with any evaluative or descriptive study. As Chaplin (1996) writes "Evaluation is a subject which usually receives a mixed response from community health initiatives and community health development projects. While some regard it as a useful tool, others see it as a detraction from the main emphasis of their work" (p 2).

Some initiatives may differ in philosophy to current treatment policy. For instance, a parents group might disagree with the substitute prescribing approaches of some services on the grounds that their child is continuing to take drugs. Broader infection 
control and crime prevention imperatives may be overlooked in rehearsing this argument. Likewise, treatment services may view community-led initiatives with suspicion and hostility. In some cases, groups may be "frozen out" i.e. being starved of resources and having access to critical decision-makers denied.

We argue that the paucity of evaluative literature is a result of community-led initiatives being on the margins of prevention and treatment approaches. Several service directories outline community based services (HEBS 1997), (HMSO 1991), (Department of Health 1996) but fall short of offering rigorous analysis of the effectiveness of these initiatives in achieving their stated objectives. Few relate to initiatives that are genuinely community inspired and sustained.

Often, even quite established community services are excluded from reports on the local and national strategy. For instance the Department of Health Task Force to review services for drug users in England (1996) did not consider community initiatives in their review. They did, however, refer to self help groups and were critical of the lack of systematic evaluation.

What works? Current evidence and dilemmas

Areas of deprivation are often associated with higher drug use (Leitner, Shapland and Wiles 1993) and there may be a concern that promotion of a drug-related initiative will further stigmatise the area and this, in turn, is likely to impact upon local political and resident involvement and support. Furthermore drug users themselves, may be reluctant to identify themselves since the distinction between user, dealer and habitual 
thief may be blurred and may change from time to time as can the views of the community with respect to the drug users in its midst. This leads to a situation of potential double marginalisation for drug users from the community: They ... associate a drug user as an entity that isn't part of the community. You know, it's like if you're a drug user you're not a member of the community (Daker-White 1997, $\mathrm{p}$ 223).

Community-led responses have taken a number of approaches. To assess the current evidence on 'What works?', we have defined community responses to drug problems under five banners: self-help groups; parents' groups, residents' groups, community development groups and diversionary activity groups for ease of discussion.

These categories are not, of course mutually exclusive and with most examples, a significant blurring of the boundaries is evident. Most self-help groups such as the Junkkiebonden in the Netherlands and Mainliners in England in the 1980s, were inspired by professional drugs workers (Korf, 1999; Yates \& Gilman, 1990) and most are now either funded as service providers in their own right or have relocated within an existing drug service. Many residents groups will include some parents or partners of drug/alcohol misusers. Many will have originated from community policing initiatives around the organisation of Neighbourhood Watch networks.

\section{Self Help Groups}

Self-help Groups are those initiatives that have been founded mainly by current or exdrug users e.g. Narcotics Anonymous. Self help groups can perform many functions 
for people, including providing a foundation for people to move into more mainstream activities, providing solutions to problems, or an alternative to mainstream activities (Burns \& Taylor, 1998). Self-help groups may also be "ginger" groups formed specifically to provide a consumer voice for drug users receiving treatment services (Yates and Gilman, 1990); or may start out as such.

Self help groups offer a potentially useful tool against exclusion, but there are concerns about the groups in terms of potential lack of accountability, or being overromanticised (Burns \& Taylor, 1998). There are also concerns about self help typically providing services to mainly middle class people whilst specialist agencies may focus on working class people (Daker-White 1997). Potentially, self help groups have the capacity to facilitate a progression from individuals seeking support, to exploring the meaning of social issues, to gaining a wider societal understanding of issues, through to taking action on a community level about the social issue (Holland, 1992). However the commitment of many self-help groups concerned with drug issues to be non-political, means that such participation is unlikely.

Formal interventions into a self-help setting often results in them being destroyed by external regulations, making it an area in which it is difficult to have policy that includes without destroying (Burns \& Taylor, 1998).

Exceptionally, the Pelican self help initiatives in Belgium have evaluated their work. Since 1981, professional self-help group meetings run by Pelican have been aimed at preventing any kind of dependence, i.e.: drug abuse and its consequences, addictions related to alcohol, medicines, food, relationships, gambling, drugs substitutes, co- 
dependency and so on. The organisation strives for the development of social values, respect and non-violence within the society. The group started up its activities in cooperation with Alcoholics Anonymous but gradually grew away from this model. Pelican organises professional self-help group sessions which are open, free, anonymous and aimed at both young people and adults. In terms of the results achieved, $20 \%$ of the people involved are actually reducing their dependence, while this improvement is somewhat less for another $20 \%$. In terms of improvements in the long-term, there was no change for $15 \%$ of the participants. For $40 \%$ of the participants who joined the group, it has been impossible to assess the moral values that Pelican hopes its participants will adopt (Source: EDDRA Database).

Klee \& Reid (1995) conducted a feasibility study on behalf of the Home Office Drugs Prevention Initiative (now the Drugs Prevention Advisory Service) which examined the possibility of encouraging the establishment of self-help groups for amphetamine users. They found that many regular users were in cohesive social groups that generally included more than one influential peer. The majority was in contact with services but usually through their outreach components rather than the service bases themselves. They concluded that these groups were markedly different culturally from opioid-using groups; that they were genuinely concerned about the health and well-being of their members; and that there was considerable scope for peer-led interventions.

However, for such groups to flourish, the existing treatment 'establishment' will be critical in supporting and encouraging their development and recognising that the central philosophy of such groups will almost certainly differ fundamentally from 
those of 'professional' agencies. Certainly, supportive relationships are by no means universal, and some Narcotics Anonymous groups have claimed that they have found it difficult to continue due to the 'cynical' attitude of local drug services (Wells, 1994).

Parents Groups

Across the UK, a number of Parents Groups have been initiated by the partners or other relatives of problem drug users. These groups appear to be predominantly female in constitution - mainly mothers. In some instances, the groups have been instigated by treatment services as family support groups for their clients. Of these, some run a structured course of information and support sessions. However, there are few examples of these and no evidence that such an approach has ever been evaluated.

A larger number of parents groups have been instigated by parents themselves in relatively small localities. A number of parents groups (both self-inspired and instigated by organisations) have aimed to provide structured education and information for parents of problem drug and alcohol users. The range of services provided by such organisations includes telephone helplines (Parents Anonymous, Bolton), information and advice (Gallowgate Parents Group, Glasgow) and classroom inputs (Jan \& Paul Betts, Highland). One initiative in Spain (EDDRA Database, 2000) has been evaluated in some detail.

Organisations in Barcelona identified the need to find the best way to reach parents who never attended training sessions for parents. The National Plan on Drugs 
provided part of the financial support. The main objective was to evaluate and compare the efficiency of three commonly used methods for training parents in the prevention of drug abuse: a) course of talks (4 hours); b) videos sent to the parents' homes; and c) booklets sent to the parents' homes.

The contents of the three methods were basically the same, the only difference being the material support (medium) in which the information was presented. The target groups were composed of 3,686 parents of primary school children between the ages of 6 and 11 attending 3 different types of school, situated in both inner-city and suburban settings.

An experimental study was undertaken, comprising 4 groups chosen at random, and with questionnaires completed before and afterwards. The questionnaires collected the following data: information about drugs (15 questions), parents' attitudes towards bringing up children (15 questions). The post-test questionnaire also included a number of questions in order to assess the impact on participants and the effectiveness of the methods used, the quality, length and clarity of the information they gave, their interest in the subject, and their own subjective views.

The main results were: a) the 3 methods used increased parents' knowledge of drugs and broadened their attitudes towards educating their children in the prevention of drug abuse; b) the video achieved a greater impact than the booklet or short talks; and c) the participants' subjective views about the methods used were positive. 
Similar initiatives have been reported upon in England (Arora \& Khatun, 1998; Marriott, undated). Again, the aim has been to use a variety of methods to influence knowledge and awareness levels within a target population of parents in order to support them in discussing drugs and alcohol issues with their children. It should be noted however, that these initiatives are aimed at parents of young people who may be using drugs or alcohol or who may be at risk of so doing. Parents in these initiatives have been targeted because of a perception that levels of knowledge within these specific groups are low; either for reasons of ethnicity and culture, or for geographical access to information reasons etc. Initiatives of this kind face evaluation dilemmas as aims, objectives and outcomes may address what the self-selected groups of parents who have already identified (or believe that they have identified) a drug problem within their own families.

Parents Against Drug Abuse, North West England is a well-established group. Their activities have included the publication of an instructional manual, Starting your own group: A guide for parents and concerned citizens working together for the good of the community. The group was also responsible for the commissioning of a large attitudinal survey of schoolchildren in the Wirral area and has appointed a part-time development worker. A study undertaken by the University of Liverpool (Todhunter, 1993) examines the process by which the group established itself from its early beginnings as a small mutual support network. However, the study falls short of an evaluation in any detail of the effectiveness of the organisation. The general conclusion was that parents and partners were an under-utilised resource. 
In our research, key informants in drug services have expressed concerns that responding to the perceived needs of parents or partners groups may be to collude with a defence response which avoids painful introspection. Unsurprisingly, we were unable to find any published literature that dealt with this extremely sensitive area.

\section{Residents Groups}

Whilst Parents Groups are more likely to concentrate their efforts on mutual support and developments which will benefit problem drug users, Residents Groups will tend to be different at least in the focus of their concerns. Here, groups may be formed around a need to "do something" about drug related behaviour which has a visible impact including vomit, drug dealing in shared access areas of multiple occupancy dwellings, noise disturbance, acquisitive crime and mugging.

This may lead to an incomplete local 'snapshot' of the issues and possible solutions emerging from the local community. The 'realities' of the problem may remain 'hidden' and therefore only certain aspects of community concerns may be manifested into solutions based on the visible side of the drug concerns. Initiatives may miss issues such as absenteeism from school or work which is linked to drug use. Much of the breadth of drug problems remain hidden from community gaze and therefore may be not be addressed although contributing to local concerns within the bigger picture.

Residents' groups frequently evolve from a response to a specific publicised critical incident. In the Cranhill area of Glasgow, the death, by heroin overdose, of a young boy ignited long term concerns regarding the use of drugs by young people on the 
scheme and the issue of drug-dealing in the area. This led to the establishment of the group Mothers Against Drugs. In other areas, the closed nature of a locality can inhibit the adoption and maintenance of a community-based initiative.

Of course, there are exceptions. In an account provided by one of our key informants about their experiences in Dublin it was reported that in one case, a particular community led initiative of parents concerned by the presence of drug dealers in their locality formed a group that developed into a high profile 'vigilante' group. With considerable emotional investment, the goals, activities and outputs of the group were explicitly illegal in nature. Naturally this type of activity could not be externally assessed and reported on but in this particular case, the goals of the group developed into a community based solution that was led by the Health Board and subsequently assessed and reported upon.

\section{Community Development Groups}

Some examples exist of community groups that have originally been inspired by an individual or group of individuals from outside the community. Most often, these have been youth workers or community development workers with a remit to initiate work within the local community. Quite often the target group has been young people experimenting with drugs or at risk of doing so.

Community initiatives are identified as being effective for getting the community itself to identify the needs of community members, but there can be concerns that it can lose theoretical basis (Bagnall \& Fossey 1996). 
The Home Office and the Drugs Prevention Initiative (now Drug Prevention Advisory Service) have compiled information about the community-initiated projects that they have supported (DPI \& Home Office, 1998). These include:

$>$ A community drugs prevention project in Wolverhampton. This project provides advice and support to local community groups.

Development of partnership in Essex (including a Romany community) by provision of a community development worker project. The partnership will work to develop drugs prevention approaches.

$>$ In Merseyside a project using action research in eight different areas provided the basis for community supported action plans.

Development of a drugs prevention programme in East London by developing a partnership between a community, local authority and other organisations.

$>$ Using links between parents and schools in Northumbria to develop effective community drugs prevention strategies.

$>$ Preparation of a guide to drugs prevention, providing training and education to the community by involving a West Yorkshire community in preparing the material.

A project in Greater Manchester that focuses on training community groups.

Across these examples of community involvement there are a number of identified points of good practice. These include early engagement with the community and an accurate assessment of the community's need. This will allow for community perceptions to be matched with other indicators of need. Gathering of local knowledge provided good information about constraints, such as time, and local 
factors to consider, such as cultural diversity, level of community involvement and appropriate group to deliver services (DPI \& Home Office, 1998).

Finally the experience of the Ghar Ghar (Popping in) Initiative (Dobson, Gupta, Hussain \& Rogerson 1999) where a rolling programme of training youth and community leaders to influence levels of drug awareness within the Asian community in a town in North England, indicates the need for flexibility in planning and implementing initiatives. The initiative is a good example of how health and educational professionals can work with community leaders to provide agreed objectives but that these objectives should be mutually agreed in advance of the initiative and subject to regular review during implementation

\section{Diversionary Activity Groups}

Whilst strictly speaking, this last category describes a type of activity rather than a type of group, we felt that these groups were so distinctive in their methodology that they warranted a separate classification. Diversionary activities could be classified as activities, which might provide an opportunity for enjoyment or excitement for the target group as an alternative to drug and/or alcohol, use. Often, the diversionary activities chosen will be sports based - forming a local football team, taking groups of young people absailing or whitewater rafting. Generally the philosophy behind this choice, where it has been articulated at all, is that so-called "adrenalin rush" activities are well placed to mount a direct challenge to the physical excitement that drugs offer. 
There are numerous examples of diversionary (often sports orientated) interventions. However, these are often initiated in partnership with existing organisations as opposed to being community initiated. An example of this is the action research project into sport and drugs education (Forrest, Green, Allison, Boyd, \& Twaddle 1998). The effectiveness of this sport activity based intervention was rated as good for the coaches involved, with limited effect demonstrated amongst the young people involved and identification of a need for longer term monitoring.

The Waltham Forest Drugs Action Team and local people who were concerned with minimising the harm of drugs and alcohol on young people developed an intervention based on two football tournaments. Key factors to the success of this initiative came about through a partnership between the agencies and community involved. The process of developing the intervention aimed to allow enough time and agency commitment to make the intervention work. The project was effective at distributing resources to young people. However the project although being community initiated was not community led (Burgess 1998).

Calton Athletic is a group based on a 12-step recovery programme operating with a self-help framework. Calton Athletic set up their School Drug Prevention Project in 1995. The project involves sessions with pupils built around 3 workshops - 'Cannabis to chaos', Life of a drug addict' and 'Effects on the Family" - all of which rely heavily upon personal testimonials by Calton Athletic group members (McKeganey \& McPike 1997). The Carlton Athletic initiative provides a good example of community initiated and led intervention. However concerns were raised in the evaluation of the project with regard to accountability, coherence (including with 
other educational inputs) and adherence to good practice (McKeganey \& McPike 1997). The evaluation was limited to an analysis of the educational efficacy of the project workshops and did not examine the organisation's capacity to reduce/eliminate drug use amongst group members.

Other initiatives - often arising out of youth work and community development have not necessarily had a specific drugs or alcohol focus. Rather, they have aimed to provide young people "at risk" in socially deprived areas with alternative activity experiences; usually in conjunction with other youth work interventions taking place in situ.

Finally, some examples exist of diversionary activity on an individual basis. Thus some problem drug/alcohol offenders have been diverted into community service orders although there appears to be some resistance to this in some social work departments; mainly on the grounds that regular intoxication limits the type of activity available (on health and safety grounds) and militates against reliable attendance. South (1990) has described the service provided by the organisation Community Service Volunteers whereby people with drug problems are placed in a variety of community settings to work as volunteers. Over a three-year period, 70 people were placed and some of these went on to study qualifications and to undertake other community work.

\section{Conclusion}

Not only are community initiatives frequently elusive and profoundly varied in nature but these very qualities have contributed to their under-representation in the literature. 
Groups may often nurse a lingering sense of grievance against existing service providers and planners and their perceived failure to respond in a supportive way to the group or provide services in line with the philosophy of the group. Some groups may, by their very nature and composition elicit suspicion and, occasionally, open hostility from service providers and planners. Even where initiatives are welcomed and supported, they can be hard to sustain, relying - as they often do - on the commitment and energy of a single individual or small group of activists.

Examples of community led or community based responses to concerns over drug issues show a variety of initiatives. Common responses include educational programmes, sport or activity-based programmes and self help. The literature does provide a greater amount of information about initiatives that are delivered into the community as opposed to initiated by the community. This could be for a number of reasons, including the absence of readily accessible literature for community led interventions and the presence of formal evaluations of interventions that are community delivered. Whether the disparity between community led and community based services being discussed in literature actually refers to current practice may warrant further investigation.

There are a number of issues concerned with evaluation that relate specifically to community led initiatives. There needs to be consideration that evaluation becomes a process that is not daunting, but helpful to communities. This includes ensuring that values of community development, processes and outcomes are considered when evaluating a service. 
There are a number of commonly identified elements that exist in successful community responses. The challenge to replicating these models of good practice are issues concerned with providing resources to support community participation and to develop community led initiatives. The message from the literature is relatively clear; community led initiatives are achievable, but it is a process that must be supported by current organisations in providing support, expertise, guidance and resources.

The very nature of the topic of this review immediately issued a challenge to reviewing literature. The availability of readily accessible literature on community based or community-initiated projects is poor. A more detailed review of community initiated projects based on the collection of unpublished material and interviews would be a very worthwhile exercise.

\section{Acknowledgements}

This article is based on the conduct of a commissioned effectiveness review for the Greater Glasgow Health Board. The views expressed here are those of the authors and do not necessarily reflect the views of the Greater Glasgow Health Board. We wish to thank Susan Kerr, GGHB and Rebekah Pratt.

\section{REFERENCES}

Arora R and Khatun (1998) No to nasha, Drugs, alcohol and tobacco use in the Bradford's Asian Communities. Race Relations Research unit in conjunction with Bradford and District Training and Enterprise Council 
Bagnall, G. \& Fossey, E. (1996) Alcohol Education Initiatives in Scotland. Drugs: education, prevention and policy. 3, 3, pp 249 - 265.

Burgess, G. (1998) “Do It Clean” A Multi-Agency Project in Waltham Forest to Promote Drugs Awareness Through Football. Evaluation Report. London Borough of Waltham Forest.

Burns, D. \& Taylor, M. (1998). Mutural aid and self-help: Coping strategies for excluded communities. Joseph Rowntree Foundation.

Daker-White, G. (1997). Drug users' access to community-based services. Health \& Place. 3, 4.

Dobson, Gupta, Hussain \& Rogerson (1999) Ghar Ghar (Popping in) Initiative

Drugs Prevention Initiative \& Home Office (1998). Guidance on Good Practice. London: Home Office.

Drugs Prevention Initiative (Scotland) (1998). A Guide to the Community's Role in Drug Prevention. Glasgow Drugs Prevention Team.

Evaluation of different methods for parent training in the prevention of drug abuse.

(SPAIN), EDDRA database_http://www.emcdda.org/databases/databases_eddra.shtml

Forrest, J., Green, B., Allison, P., Boyd, B. \& Twaddle, G. (1998) Sport \& Drug Education Action Research Project. Glasgow: University of Strathclyde. 
Health Education Board Scotland (1997) Drugs in Scotland: Informing the challenge. Edinburgh: HEBS.

HM Government (1998) Tackling Drugs To Build A Better Britain The Government's ten year strategy for tackling drug misuse (London, HMSO) http://www.officialdocuments.co.uk/document/cm39/3945/3945.htm

HMSO (1991). Lord President's Report on Action Against Alcohol Misuse. London: HMSO.

Holland, S. (1999). From social abuse to social action. In Ussher, J. \& Nicolson, P. (eds) Gender Issues in Clinical Psychology. London: Routledge.

Klee, H and Reid P (1995) Amphetamine-Misusing Groups: a feasibility study of the use of peer group leaders for drug prevention work among their associates. Drugs Prevention Initiative London: Home Office,

Kooyman, M. (2000) The history of therapeutic communities: A view from Europe, in: Rawlings, B. \& Yates, R. (Eds.) Therapeutic Communities for the Treatment of Drug Users (London, Jessica Kingsley) forthcoming.

Korf, D., Riper, H., Freeman, M., Lewis, R., Grant, I., Jacob, E., Mougin, C. \& Nilson, M. (1999) Outreach Work Among Drug Users in Europe: Concepts, practice and terminology (Lisbon, EMCDDA Insight Series 2) 
Leitner, M., Shapland, J. \& Wiles, P. (1993). Drug Usage and Drugs Prevention: The views and habits of the general public. London: HMSO.

Marriott R (undated) Mount Wise Youth Project: Audit of services for DATA in relation to drug use.

McKeganey N. \& McPike, M. (1997). A Process Evaluation of Carlton Athletic's Drug Prevention Team. Centre for Drug Misuse Research: Glasgow: University of Glasgow.

Parkin S and Mckeganey N (2000) The rise and rise of peer education approaches. Drugs: Education, Prevention and Policy 7: 3: 292-310.

PELICAN -self help group. EDDRA database

Scottish Office (1999) Towards a Healthier Scotland: White Paper on Health. London: The Stationery Office.

Scottish Office (1999). Tackling Drugs in Scotland: Action in Partnership London: The Stationery Office.

Scottish Office. (1994). Drugs in Scotland: Meeting the Challenge. London: The Stationery Office. 
Scottish Office (1999) Tackling Drugs in Scotland: Action in partnership (Edinburgh, HMSO)

South N. (1990) Third (Final) Report on two CVS Action Schemes Referring Drug (legal and illegal) and Alcohol Users to Volunteer Placements in North London and Mid-Essex (London, ISDD)

Todhunter C. (1993) The P.A.D.A. development initiative evaluation (Liverpool, University of Liverpool)

Wells, B. (1994) Narcotics Anonymous (NA) in Britain, in: STRANG, J \& GOSSOP, M (Eds.) Heroin Addiction and Drug Policy: The British System (Oxford, Oxford University Press)

Yates R, Morris S and Pratt R (2000) Effective responses to alcohol and drug concerns in the community: Evidence, dilemmas and solutions Report prepared for the Greater Glasgow Health Board Health Promotion Department.

YATES, R. \& GILMAN, M. (1990) Seeing More Drug Users: Outreach work and beyond (Manchester, Lifeline Project) 